\title{
Prognosis of umbilical cord prolapse: experiency of an African maternity
}

\author{
Charles Kakou*, Raoul Kasse, Hervé Koime, Arthur Kouame, Denis Effoh, Serge Boni
}

Department Gynecology and Obstetrics, Cocody University Hospital, University Felix Houphouet Boigny, Abidjan, Côte d'Ivoire

Received: 25 August 2017

Accepted: 02 September 2017

\author{
*Correspondence: \\ Dr. Charles Kakou, \\ E-mail: kakoucharles@yahoo.fr
}

Copyright: () the author(s), publisher and licensee Medip Academy. This is an open-access article distributed under the terms of the Creative Commons Attribution Non-Commercial License, which permits unrestricted non-commercial use, distribution, and reproduction in any medium, provided the original work is properly cited.

\begin{abstract}
Background: Assess the fetal prognosis of umbilical cord prolapse (UCP) at Cocody University Hospital. Methods: It was a cross-sectional, descriptive and case-control study about 92 cases of umbilical cord prolapse beating. It took place over a period of 3 years from 1 January 2013 to 31 December 2015.

Results: The frequency of the umbilical cord prolapse beating was $0.73 \%$. The patients came from other maternity in $84.8 \%$. Upon arrival in our maternity, therapeutic attitude was dominated by the positioning of Trendelenburg (73.9\%). The c-section was performed in $63 \%$ of cases. The fetal prognosis was bad; neonatal mortality was $41.3 \%$ at 5 minutes of life against $9.8 \%$ in the control group. The factors aggravating the fetal prognosis were the long delay between the occurrence of the umbilical cord prolapse and childbirth, the delivery mode and the small birth weight. Conclusions: The late management and the evacuations negatively affect the fetal prognosis. Improving fetal prognosis requires quick care and the provision of an efficient technical platform surrounding maternity.
\end{abstract}

Keywords: Delivery mode, Fetal prognosis, Umbilical cord prolapse

\section{INTRODUCTION}

The umbilical cord prolapse (UCP) is an obstetrical accident occurring during labor. It causes a significant perinatal mortality. The quick realization of a c-section should permit to save the fetus. The umbilical cord prolapse is a rare obstetric situation (less than 1\%); but very urgent with significant perinatal mortality of 36 345/1000 births. ${ }^{1}$

This obstetrical accident is little studied in Côte d'Ivoire. It became necessary to carry out this study to assess the fetal prognosis of the umbilical cord prolapse beating in our maternity of Cocody University Hospital. It is a structure referenced which receives the obstetrical emergencies from surrounding hospitals.

\section{METHODS}

It was a cross-sectional, descriptive and case-control study over a period of three (3) years, from January $1^{\text {st }}$, 2013 to December $31^{\text {st }}$, 2015. Patients, considered as case of the study, were all cases of umbilical cord prolapse beating observed in the parturient with a gestational age greater than or equal to 28 weeks of amenorrhea of pregnancy singleton. 92 cases of prolapsed umbilical cord beating recruited. The control group was represented by parturient with a gestational age greater than or equal to 28 weeks of amenorrhea carrier of a singleton pregnancy and without umbilical cord prolapse. The controls were selected on the basis of a case for a control. So, for a umbilical cord prolapse identified case, the control was selected from a couple mother - child on the same day 
with a mother of the same parity, the same age or near age ( \pm a year). We have not been included in the study, the parturient with a gestational age less than 28 week of amenorrhea and all cases of umbilical cord prolapse not beating before childbirth. The data collected was entered and analysed using EPI INFO 6.0 software. The comparison of proportions was made by the test of the $\mathrm{Chi}^{2}$ with a $5 \%$ significance level. Thus, tests giving a value of $\mathrm{P}<0.05$ were considered significant.

\section{RESULTS}

\section{Frequency}

During the study period, we recorded 12549 deliveries, 121 cases of umbilical cord prolapsed; 29 no beating on the admission and 92 beating. The average frequency of UCP beating was $0.73 \%$. During the study period, we recorded 12549 deliveries, 121 cases of umbilical cord procidency, of which 29 were non-winged at admission and 92 cases. The average frequency of PCO flying was $0.73 \%$ (Table 1 ).
Table 1: Annual distribution of umbilical cord prolapse beating.

\begin{tabular}{|llll|}
\hline Years & $\begin{array}{l}\text { Number } \\
\text { of UCP }\end{array}$ & $\begin{array}{l}\text { Number of } \\
\text { delivery }\end{array}$ & $\begin{array}{l}\text { Frequency } \\
(\%)\end{array}$ \\
\hline 2012 & 33 & 4115 & 0,80 \\
\hline 2013 & 32 & 4268 & 0,75 \\
\hline 2014 & 27 & 4166 & 0,65 \\
\hline Total & 92 & 12549 & 0,73 \\
\hline
\end{tabular}

\section{Clinical data}

Clinical data are presented in the Table 1. The parturient presenting an UCP were more often evacuated from surrounding maternity $(84,8 \%$ cases $)$ with an alteration of fetal heart rate in $41.3 \%$ of cases compared to the control group $(7.6 \%)$.

The breaking of the waters had been spontaneous more often $(78.3 \%)$. The fetus was in breech position in $34.8 \%$ of cases of UCP versus $7.6 \%$ in controls.

Table 2: Clinical examination data.

\begin{tabular}{|c|c|c|c|c|c|c|}
\hline \multirow{2}{*}{\multicolumn{2}{|c|}{ Clinical examination data }} & \multicolumn{2}{|l|}{ Case } & \multicolumn{2}{|l|}{ Control } & \multirow[b]{2}{*}{$\mathbf{X}^{2}$ et $\mathbf{P}$} \\
\hline & & $\mathrm{N}(=92)$ & $\%$ & $\mathrm{~N}(=92)$ & $\%$ & \\
\hline \multirow[b]{2}{*}{ Admission mode } & Patient coming from house & 14 & 15,2 & 46 & 50 & \multirow{2}{*}{$\begin{array}{l}X^{2}: 25.32 \\
P: 0.000\end{array}$} \\
\hline & Evacuated from other maternity & 78 & 84,8 & 46 & 50 & \\
\hline \multirow{2}{*}{ Fetal heart rate (FHR) } & $120 \leq \mathrm{FHR} \leq 160 \mathrm{bpm}$ & 54 & 58,7 & 85 & 92,4 & \multirow{2}{*}{$\begin{array}{l}X^{2}: 28.27 \\
P: 0.000\end{array}$} \\
\hline & FHR $<120$ ou $>160 \mathrm{bpm}$ & 38 & 41,3 & 07 & 7,6 & \\
\hline \multirow{2}{*}{ Rupture of membrane } & Spontaneous & 80 & 87,0 & 41 & 44,6 & \multirow{2}{*}{$\begin{array}{l}X^{2}: 43.68 \\
P: 0.000\end{array}$} \\
\hline & Artificial & 12 & 13,0 & 51 & 55,4 & \\
\hline \multirow{3}{*}{ Fetal presentation type } & Cephalic & 55 & 59,8 & 83 & 90,2 & \multirow{3}{*}{$\begin{array}{l}X^{2}: 22.72 \\
P: 0.000\end{array}$} \\
\hline & Breech & 32 & 34,8 & 07 & 07,6 & \\
\hline & Transversal & 05 & 05,4 & 02 & 02,2 & \\
\hline \multirow{3}{*}{ Cervical dilatation $(\mathrm{cm})$} & $<4 \mathrm{~cm}$ & 19 & 20,6 & 21 & 22,8 & \multirow{3}{*}{$\begin{array}{l}\mathrm{X}^{2}: 1.90 \\
\mathrm{P}: 0.386 \\
(\mathrm{~ns})\end{array}$} \\
\hline & $\geq 4 \mathrm{~cm}$ & 54 & 58,7 & 59 & 64,2 & \\
\hline & Complete & 19 & 20,6 & 12 & 13,0 & \\
\hline \multirow{3}{*}{ Degree of UCP } & $1^{\text {st }}$ degree & 19 & 20,6 & & & \\
\hline & $2^{\text {th }}$ degree & 41 & 44,6 & & & \\
\hline & $3^{\text {rd }}$ degree & 32 & 34,8 & & & \\
\hline
\end{tabular}

Table 3: Distribution of the pregnant according to the waiting treatment.

\begin{tabular}{|lcc|}
\hline & Case \\
\hline Waiting treatment & N & $\%$ \\
\hline Trendelenburg position & 68 & 73,9 \\
\hline Repression of presentation & 06 & 06,5 \\
\hline Humidification of the umbilical cord & 02 & 02,2 \\
\hline other* & 16 & 17,4 \\
\hline Cases who received a Trendelenburg position, a repression of \\
fetal presentation and a humidification of the umbilical cord.
\end{tabular}

Table 4: Distribution of the pregnant according to delivery mode.

\begin{tabular}{|lclll|}
\hline Delivery mode & Case & \multicolumn{3}{c|}{ Control } \\
\hline Caesarean-section & $\mathbf{N}$ & $\mathbf{\%}$ & $\mathbf{N}$ & $\mathbf{\%}$ \\
\hline Vaginal delivery & 34 & 63,0 & 28 & 30,4 \\
\hline $\mathrm{X}^{2}=22,69, \mathrm{ddl}=1, \mathrm{p}=0,000(\mathrm{~S})$. & & & \\
\hline
\end{tabular}

\section{Obstetric care}

There are presented in Tables 3 and Table 4. 


\section{Delay diagnosis-delivery}

The time period between diagnosis and childbirth was less than $2 \mathrm{~h}$ at $64.1 \%$ of cases compared with $42.4 \%$ in the controls.

\section{Fetal prognosis}

The fetal prognosis and the aggravating factors are listed in Tables 6 and 7 . We noted $41.3 \%$ of neonatal deaths against $9.8 \%$ in the controls; $17.4 \%$ of bad Apgar score against $4.3 \%$ in the controls.

The vaginal delivery has been harmful in case of an umbilical cord prolapse $(p=0.000)$. The type of presentation did not influence the Apgar score in 5 minutes. The best Apgar scores at 5 minutes have been observed in children born within a period of less than 2 hours delivery. The low birth weight contributed to the neonatal death.

Table 5: Time period between diagnosis and delivery.

\begin{tabular}{|llllll|}
\hline Time period $(\mathrm{mn})$ & Case & \multicolumn{2}{c|}{ Control } \\
\hline$\leq 30$ & $\mathbf{N}$ & $\mathbf{\%}$ & $\mathbf{N}$ & $\mathbf{\%}$ \\
\hline $31-60$ & 14 & 15,2 & 64,1 & 11 & 12,0 \\
\hline $61-120$ & 11 & 12,0 & 15 & 16,3 \\
\hline $121-180$ & 34 & 36,9 & & 13 & 14,1 \\
\hline $181-240$ & 11 & 12,0 & 16 & 17,4 \\
\hline$>240$ & 09 & 09,8 & 05 & 05,4 \\
\hline Total & 13 & 14,1 & 32 & 34,8 \\
\hline
\end{tabular}

$\mathrm{X}^{2}=20.45, \mathrm{ddl}=5, \mathrm{p}=0.000(\mathrm{~S})$, Minimal: $3 \mathrm{mn}$, Mean: $2 \mathrm{~h} 24 \mathrm{mn}$, Maximum: $16 \mathrm{~h} 47 \mathrm{mn}$.

Table 6: Distribution of newborns according to APGAR score at 1 minute and at 5 minutes.

\begin{tabular}{|c|c|c|c|c|c|c|}
\hline \multirow{2}{*}{ State of newborn at birth } & & \multicolumn{2}{|c|}{ Case } & \multicolumn{2}{|c|}{ Control } & \multirow{2}{*}{$\mathbf{X}^{2}$ et $\mathbf{P}$} \\
\hline & & $\mathbf{N}$ & $\%$ & $\mathbf{N}$ & $\%$ & \\
\hline \multirow{2}{*}{ APGAR score at 1 st minute } & $1-6$ & 77 & 83,7 & 29 & 31,5 & \multirow{2}{*}{$\begin{array}{l}X^{2}: 51.27 \\
p: 0.000\end{array}$} \\
\hline & $\geq 7$ & 15 & 16,3 & 63 & 68,5 & \\
\hline \multirow{3}{*}{ APGAR score at 5 minutes } & 0 & 38 & 41,3 & 09 & 09,8 & \multirow{3}{*}{$\begin{array}{l}X^{2}: 39.46 \\
P: 0.000\end{array}$} \\
\hline & $1-6$ & 16 & 17,4 & 04 & 04,3 & \\
\hline & $\geq 7$ & 38 & 41,3 & 79 & 85,9 & \\
\hline
\end{tabular}

Table 7: The prognostic factors.

\begin{tabular}{|c|c|c|c|c|}
\hline \multirow[t]{2}{*}{ Prognostic factors } & \multicolumn{4}{|c|}{ APGAR Score at 5 minutes of live } \\
\hline & $0(\mathrm{n}=38)$ & $<7(\mathrm{n}=16)$ & $>7(\mathrm{n}=38)$ & Total $(n=92)$ \\
\hline \multicolumn{5}{|c|}{ Delivery mode, $\mathrm{X}^{2}=37.5, \mathrm{p}=0.000(\mathrm{~s})$} \\
\hline Caesarean-section & $10(17,2 \%)$ & $14(24,1 \%)$ & $34(58,7 \%)$ & $58(63 \%)$ \\
\hline Vaginal delivery & $28(82,3 \%)$ & $2(5,9 \%)$ & $4(11,8 \%)$ & $34(37 \%)$ \\
\hline \multicolumn{5}{|c|}{ Fetal presentation type, $X^{2}=4.49, p=0.105(n s)$} \\
\hline Cephalic & $26(47,3 \%)$ & $6(10,9 \%)$ & $23(41,8 \%)$ & $55(59,8 \%)$ \\
\hline Other & $12(32,4 \%)$ & $10(27 \%)$ & $15(40,6 \%)$ & $37(39,2 \%)$ \\
\hline \multicolumn{5}{|c|}{ Time between diagnosis and childbirth, $X^{2}=14.27, p=0.000$ (s) } \\
\hline$<120 \mathrm{~min}$ & $16(27,1 \%)$ & $14(23,7 \%)$ & $29(49,2 \%)$ & $59(64,1 \%)$ \\
\hline$>120 \mathrm{~min}$ & $22(66,7 \%)$ & $2(6,1 \%)$ & $9(27,2 \%)$ & $33(35,9 \%)$ \\
\hline \multicolumn{5}{|c|}{ Birth weight, $X^{2}=12.68, p=0.001(s)$} \\
\hline$<2500 \mathrm{~g}$ & $15(71,5 \%)$ & $4(19 \%)$ & $2(9,5 \%)$ & $21(22,8 \%)$ \\
\hline$>2500 \mathrm{~g}$ & $23(32,4 \%)$ & $12(16,9 \%)$ & $36(50,7 \%)$ & $71(77,2 \%)$ \\
\hline
\end{tabular}

\section{DISCUSSION}

The umbilical cord prolapsed is a rare obstetrical accident; less than $1 \%$ in our series (Table 1). In the literature, the incidence of the prolapsed cord is low between $0.12 \%$ and $0.18 \% .^{2-3}$ Our high rate is due to selection bias, related to the recruitment mode (Table 2) with $84.8 \%$ patients were evacuated from surrounding 
hospitals. This high rate of patients evacuated confirmed the reference nature of our structure, the Cocody University Hospital (UH-C). No patient (Table 3) received during the evacuation of the entire waiting treatment advocated in the literature if umbilical cord prolapse beating namely Trendelenburg positioning, the repression of fetal presentation by vaginal one-handed, the filling of the bladder by 500 to $750 \mathrm{cc}$ of saline and the administration of (B-Mimetic). ${ }^{3}$ These gestures allow to minimize the fetal distress by promoting a decompression of the umbilical cord. The absence of these gestures can be related to neonatal mortality or a bad Apgar score at birth. We noted an acute fetal distress in $41.3 \%$ of cases compared to $7.6 \%$ in the controls. This

rate of $41.3 \%$ is higher than that of Traore $(13.5 \%)$ but close to those of Alouini and Gannard-Pechin respectively $35.1 \%$ and $52.7 \% .^{2-4}$ The high rate is related to the character feticide the umbilical cord prolapse.

The umbilical cord prolapse beating was discovered in more than half of the cases $(58.6 \%)$ more than $4 \mathrm{~cm}$ of cervical dilation. The diagnosis was made in $51 \%$ of cases to $7 \mathrm{~cm}$ of cervical dilation. The $2 \mathrm{nd}$ and $3 \mathrm{rd}$ degrees umbilical cord prolapse accounted for $79.3 \%$ of the cases. This rate is stackable to Traoré with $80.9 \%$ and other authors. ${ }^{2-5}$ In their studies, the prolapsed cord occurred during the $2^{\text {nd }}$ phase of labor in case of spontaneous rupture or more often of artificial rupture of the membranes. The fetal extraction is based on two parameters: the fetal status at time of diagnosis and the imminence of childbirth. $20.7 \%$ of patients were at full dilation, they have given birth vaginally. But in total, in $37 \%$ of patients-cases, childbirth was done vaginally, aggravating the neonatal prognosis. Vaginal delivery has been practiced in the majority of cases because of the long delay before the realization of an emergency csection. In the sub region, the sad fact is the same. ${ }^{4}$ Waiting for surgery, obstetric gestures realized were Trendelenburg positioning $(73.9 \%)$, humidification of the cord by saline $(2.2 \%)$ and the repression of the presentation by vaginal one-handed $(6.5 \%)$.

The c-section was performed for $63 \%$ of cases compared to $30.4 \%$ in controls (Table 4). In most series of literature and had relatively high rates respective $84.2 \%$ and $66.7 \% .^{2,3}$ Caesarean section is the best route of fetal extraction suited in the case of umbilical cord prolapse beating to a better fetal prognosis. ${ }^{6}$ In industrialized countries, a c-section is possible in a very short time. In France, the delay is less than or equal to 15 minutes in case of extreme emergency. ${ }^{7}$ This has been possible by the implementation of the codes 'color' which reduces the decision-birth of emergency Caesareans. ${ }^{7}$ in our series we noted $41.3 \%$ of neonatal deaths against $9.8 \%$ in the controls. In European literature, mortality ranges from 3.9 to $9.1 \% .^{3,8,9}$ While in the Sub West African region, mortality remains high: in Nigeria, Kalu et al was a similar neonatal mortality $41.3 \%$. ${ }^{10}$ Several factors contribute to worsen the fetal prognosis among which: the time period before extraction, the fetal presentation type; the delivery mode and the birth weight. Indeed, the majority of our neonatal deaths have involved children born in a delay of over 2 hours after the diagnosis. These long delays before the fetal extraction are due more often: the conditions of evacuation in patients to the UH-C, the overload of the work to the UH-C making difficult immediate support, incomplete surgical kits and lack of operating materials requiring parents to go to buy some drugs in pharmacy in town, an insufficient technical platform (a single operating for busy emergencies 24/24). In literature, the authors acknowledge that the time between diagnosis and childbirth is a fundamental prognosis factor. . $^{2,3,7,11}$

For example, for when the period before birth is more than an hour, mortality exceeds $25 \%$, while in general the authors report a mortality of $5 \%$ when the time is less than 30 minutes. ${ }^{12}$ The minimum time recorded in our series is 18 minutes while the maximum is $16 \mathrm{~h}$ with an average of 2 hours 25 minutes.

Concerning the delivery mode, the vaginal route was highly feticide if umbilical cord prolapse. We noted $82.3 \%$ of neonatal deaths in children born vaginally against $17.2 \%$ of those born by caesarean section. Thus, many authors recommend caesarean section if prolapsed, because it can reduce neonatal mortality.,6,13 For all reasons, the vaginal delivery is not appropriate in the cases of UCP if imminent delivery; contrarily to the recent study of Behbehani and al at Canada. ${ }^{14}$

The fetal presentation type is also a factor of poor prognosis. The new-born dead 5 minutes from life in the cephalic presentation are more numerous than those being breech or cross presentation. But the difference is not statistically significant in our series (see table VII) unlike a study reported in the literature. ${ }^{10} 47.3 \%$ of fetal deaths in case of cephalic presentation against $32.4 \%$ of stillborn for other presentations. The funicular compression caused by cephalic presentation contributed to this death. According to other authors, cuts the cord in non-cephalic presentations are lower and better tolerated than in cephalic presentations. ${ }^{2}$

The low birth weight was found also as bad fetal prognosis factor. In our series, there were $71.5 \%$ of deadborn children of birth weight less than $2500 \mathrm{~g}$ and $19 \%$ of bad Apgar score $(p=0.001)$. It's a risk factor found in the literature. ${ }^{3,5}$ This accident is more deleterious to newborn with small birth weight; those are already in a precarious health state.

\section{CONCLUSION}

The umbilical cord prolapse beating is little observed at the maternity of Cocody university hospital. Obstetric attitude pending the c-section was dominated by Trendelenburg positioning. The c-section was performed in $63 \%$. Neonatal mortality was high (41.3\%). The 
factors of bad fetal prognosis in our working environment were the long delay between the occurrence of the UCP and childbirth, vaginal delivery and the small birth weight. Fast care by caesarean could improve significantly the fetal prognosis. To do this, we must strengthen our technical platform.

Funding: No funding sources Conflict of interest: None declared

Ethical approval: Not required

\section{REFERENCES}

1. Kahana B, Sheiner E, Levy A, Lazer S, Mazor M. Umbilical cord prolapse and perinatal outcomes. Int J Gynecol Obstet. 2004;84:127-32.

2. Alouini S, Mesnard L, Megier P, Lemaire B, Coly S, Desroches A. Procidence du cordon: prise en charge obstétricale et conséquences néonatales. J Gynecol Obstet Biol Reprod. 2010;39(6):471-7

3. Gannard-Pechin E, Ramanah R, Cossa S, Mulin B, Maillet R, Riethmuller D. La procidence du cordon: à propos d'une série sur 23 années d'activité. J Gynecol Obstet Biol Reprod. 2012;41(6):574-83.

4. Traore Y, Dicko TF, Teguete B, Mulbah JK, Adjobi R, N'Guessan E, et al. Frequency of cord prolapse: etiological factors and fetal prognosis in 47 cases in a health center. Mali Med. 2006;21(1):25-9.

5. Hasegawa J, Sekizawa A, Ikeda T, Koresawa M, Ishiwata I, Kawabata M, et al. Japan Association of Obstetricians and Gynecologists. Clinical risk factors for poor neonatal outcomes in umbilical cord prolapse. J Matern Fetal Neonatal Med. 2015;16:1-5.

6. Uygur D, Kis S, Tuncer R, Ozcan FS, Erkaya S. Risk factors and infant outcomes associated with umbilical cord prolapse. Int J Gynecol Obstet. 2002;78:127-30.
7. Huissoud C, du Mesnildot P, Sayegh I, Dupuis O, Clement HJ, Thevenet $S$, et al. The implementation of the "color" codes reduces the decision-to-birth time for urgent Caesarean sections. J Gynecol Obstet Biol Reprod. 2009;38:51-9.

8. Boyle JJ, Katz VL. Umbilical cord prolapse in current obstetric practice. J Reprod Med. 2005;50:303-6.

9. Dilbaz B, Ozturkoglu E. Risk factors and perinatal outcomes associated with umbilical cord prolapse Arch Gynecol Obstet. 2006;274:104-7.

10. Kalu CA, Umeora O. risks factors and perinatal outcome of umbilical cord prolapsed in Ebonyi State University Teaching Hospital, Abakaliki, Nigeria. Niger J Clin pract. 2011;14:413-7.

11. Obeidat N, Zayed F, Alchalabi H, Obeidat B, ElJallad MF, Obeidat M. Umbilical cord prolapse: a 10 -year retrospective study in two civil hospitals, North Jordan. J Obstet Gynaecol. 2010; 30:257-60.

12. Guikovaty JP, Dellembach P, Lewin D. The prolapse of the cord and limbs. Traité d'obstetrrique, VOKAER. 1985;2:473-6.

13. Victory R, Penava D, Da Silva O, Natale R, Richardson B. Umbilical cord $\mathrm{pH}$ and base excess values in relation to adverse outcome events for infants delivering at term Am. J Obstet Gynecol. 2004;191:2021-8.

14. Behbehani S, Patenaude V, Abenhaim HA. Maternal Risk Factors and Outcomes of Umbilical Cord Prolapse: A Population-Based Study. J Obstet Gynecol Canada. 2016;38(1):23-8.

Cite this article as: Kakou C, Kasse R, Koime H, Kouame A, Effoh D, Boni S. Prognosis of umbilical cord prolapse: experiency of an African maternity. Int J Reprod Contracept Obstet Gynecol 2017;6: 4258-62. 